\title{
Short stature, Brussels type
}

INSERM

\section{Source}

INSERM. (1999). Orphanet: an online rare disease and orphan drug data base. Short stature, Brussels type. ORPHA:2867

This syndrome is characterised by short stature presenting in the neonatal period associated with osteochondrodysplastic lesions and facial dysmorphism. 